\title{
Some Observations on Witchcraft: The Case of the Aivilik Eskimos
}

\author{
ARTHUR E. HIPPLER ${ }^{1}$
}

\begin{abstract}
Cultural and psychological theories of witchcraft are related in order to develop a more comprehensive theory. The proposed integrative schema is applied to witchcraft among the Aivilik Eskimos. Using a theoretical approach, continuities in pre-with post-contact witchcraft are related to Eskimo "cultural personality." Changes are shown to be more illusory than real, and when real, to be related to new social and cultural circumstances in which the continuing personality pattern must operate.
\end{abstract}

RÉSUMÉ. Quelques observations sur la sorcellerie : le cas des Esquimaux Aivilik. L'auteur met en relation les théories culturelles et psychologiques sur la sorcellerie, dans le but de développer une théorie plus complète. Il applique le schème d'intégration qu'il propose à la sorcellerie chez les Esquimaux Aivilik. Par une approche théorique, il relie les continuités de la sorcellerie avant et après le contact à la "personnalité culturelle" esquimaude. Il montre que les changements sont plus illusoires que réels ; lorsqu'ils sont réels, ils dépendent de nouvelles circonstances sociales et culturelles dans lesquelles le modèle continu de personnalité doit fonctionner.

РЕЗЮИЕ. Некоторье наблюдения за колдовством на примере айвиликских әскимосов. В результате анализа культурных и психологических теорий колдовства развивается более общая теория этого явления. Предложенная обобщённая схема применяется $\kappa$ колдовству среди айвиликских эскимосов. $\mathrm{Ha}$ основе теоретического рассмотрения показано, что развитие колдовства у әскимосов, продолжающееся после контакта с белыми зююдьми, связано с их "культурной индивидуальностью". Показано также, что изменения в среде әскимосов являются скорее кажущимися, чем действительными, а в тех случалх, когда изменения всё-таки существуют, они связаны с социальными и культурными условиями, в которых действует прежний тип индивидуальности әскимосов.

\section{INTRODUCTION}

Witchcraft (and sorcery) can be defined as the systematic belief in the capacity to harm people at a distance, often by the manipulation of objects symbolic of the individual, through a form of supernatural intervention and behaviour consistent with such beliefs. The subject has been of interest to anthropologists from the late nineteenth century (DeVos and Hippler 1969), and in some form or other witchcraft appears to be nearly universal cross-culturally (Wittkower and Weidman, 1968; Fortune, 1932; and Kiev, 1962). Explanations for witchcraft have ranged from culturological through functionalist and social structural arguments to psychoanalytic and other psychological levels of analysis. General consideration is given to these explanations here but the specific aim of this paper is to analyse continuities and changes in witchcraft behaviour noted by Carpenter (1953) among the Aivilik Eskimos. (The Aiviliks are a branch of the Igulik who live in scattered communities along Roes Welcome Sound north of Hudson Bay. On

1Institute of Social, Economic and Government Research, University of Alaska, Fairbanks, Alaska. 
Southampton Island they total about 120 individuals, or roughly half the native population. The remainder belong to the Okomiut, Akianimiut, and Kidlinikmiut groups.)

An example of a social structural argument is that of Whitten (1962), who suggests that witchcraft among North Carolina Negroes is rooted not in African but in seventeenth century practices in the United States, and is continued now because of the position of Negroes in that society. Marwich (1952) using a functional analysis finds similarly that witchcraft among the Cewa in Rhodesia positively catalyzes new lineage formation by causing splits in the matriline through cross-accusations of witchcraft by lineage mates.

Both analyses, though useful, do not relate witchcraft to the individual emotional roots of practitioners or believers. The emotional dimension cannot so easily be explained by recourse to historical, cultural, or social structural levels of analysis alone.

Some researchers have attempted to go beyond this. Rosenthal and Siegal (1956) use Festinger's (1961 theory of "cognitive dissonance" (the individual's attempt to reduce "dissonance" in inconsistent belief systems by making them appear more consistent to himself in order to explain witchcraft). If the culture, they argue, does not provide adequate means for direct control over important environmental influences, people turn to supernatural aid. This more useful form of analysis, however, still leaves obscure the emotional mechanisms and cultural supports involved.

Psychoanalytic approaches have attempted to broaden and make more useful this kind of perspective. Such field workers as Boyer (1964) have suggested that witchcraft is the projection of internal aggressive feelings unacceptable to the self, and the displacement of the internalized "good" and "bad" mother onto others. This notion is based on concepts developed in psychoanalysis by such researchers, clinicians, and cross-cultural field workers, as Klein (1932), Lewin (1950), and Roheim (1940, 1950, 1952). Simply stated this theory proposes that the infant internalizes at a very early age, the "good" (that is loving, providing, always present) mother, and the "bad" (absent or angry) mother. The "bad" internalization is so uncomfortable that the child projects it outward so that the anger and hate are not felt as coming from inside of himself. A closely related phenomenon is that of paranoid ideation in which the unacceptable love object (incestuous, homosexual, etc.) is seen as an attacking object, which helps the individual defend himself against forbidden longings.

Using this set of theoretical formulations it should be possible to relate both the intensity and the form of witchcraft to certain dynamics in child rearing, such as harshness from the mother, though any such analysis would have to be based upon much more than a single factor. By itself it does not include the necessary cultural dimension which would make it a powerful theory.

Nadel $(1952,1954)$ attempted to test such an approach. His findings in four African societies, he believes, do not support the hypothesis, and he finds witchcraft to serve social structural functions. Unfortunately, Nadel does not provide precisely the kinds of socialization data that would permit an adequate evaluation of his work.

Kluckhohn (1944) however, in using the kind of approach to the study of 
witchcraft which we suggest for the Aivilik Eskimos, makes a quite convincing case for the Navajo. Navajos experience an initially nurturant childhood which at weaning becomes an intolerable round of beatings and scoldings. This we believe exacerbates the need for the child to continue the "good," "bad" split in maternal imagos, and to resist integrating the maternal picture into a single individual with good and bad aspects. Not surprisingly then, adult Navajos tend to feel that women are all either bad or good. The bad feelings of the child caused by these socialization practices are projected out and attributed to others.

Navajo society is also very cooperative with a strong ethos in favour of communal activity. Perhaps the child faced with the loss of maternal nurturance came to view the world as dangerous and hence to rely on communal activity for comfort, as well as its functional every-day uses. In any event witchcraft provides an outlet for aggressions in a society which stresses cooperation and harmony.

Thus the cultural values and beliefs integrate with the personality structure produced by the child-rearing practices to support a system of beliefs which stresses witchcraft as an explanation for disease, etc. There is no way to do justice to Kluckhohn's formulations so briefly - but the integration of levels of explanation appears evident. It is this kind of approach we suggest to analyse witchcraft among the Aivilik. The analysis is not meant, I hasten to add, as a detailed exhaustive attempt, but rather to indicate a direction for research.

\section{WITCH FEAR AMONG THE ESKIMOS}

Carpenter (1953) in reporting on witch fear among the Aivilik Eskimos, related it to insecurities in adult life such as the loss of caribou herds or the uncertainty of the fox fur trade, and notes also the effect of religious change. While these reality concerns may indeed act to precipitate pathic behaviours, this level of interpretation is insufficient to explain the form of the witchcraft, or why witchcraft should have been the response at all. A closer look at Eskimo culture and personality under conditions of culture change, however, seems not only to offer a functional explanation, but even offers some insight into the form of that witchcraft.

Eskimo cultural personality is essentially characterized by a complex of structure we term as oral optimistic fatalism. By cultural personality we mean that whole of unconscious concerns and interests, defences and coping mechanisms which can be said to characterize the members of a cultural group. Cultural personality also includes those institutionalized expressive behaviours which reflect defensively or creatively these fundamental concerns, and which are part of the shared heritage of the group. The concept permits of diversity in unconscious structures and defences, but suggests that the internalized pressure of that which is shared tends to mold the individual into a given form. My assumptions about Eskimo personality are based on my field work in Alaska, but more particularly on the Canadian field work of Briggs (1970a, 1970b), Lubart (1971), Freuchen (1931) and others included in an annotated bibliography of Eskimo sources (Hippler 1970).

The term "oral optimistic fatalism" suggests that Eskimos tend to feel the universe is benign and giving and generally good. Eskimos also tend to feel the 
universe is at times cruel and unpredictable, but the defence against angry feelings over frustration is a conscious fatalistic acceptance.

This adult attitude colours all expectations in life and it is believed, is related to the interesting polarity in Eskimo behaviour. Eskimos are generally noted for being friendly, cooperative, sharing (even of wives at times), with a strongly positive attitude toward the truth and a forthright courageous attitude toward their environment. They are also noted as gentle in child-rearing and strongly oriented toward avoiding violence and even conflict at all costs. But this does not mean that they cannot also be grasping, greedy, murderous in their jealousy over women and subject to malicious gossip and other human frailties, at the same time fearing yet needing shamanistic intervention in the real world of hunting. They have also been known to be cruel to favoured and unfavoured children, dogs and other animals, to follow taboo-ridden practices of infanticide and be subject to hysterical psychoses (often called pibloqtok or some variant).

Both of these divergent descriptions we believe to be true. They can be consistently and coherently explained, however, only by having recourse to an analysis of their underlying dynamics. These can most clearly be seen in the socialization procedures.

Initial socialization for Eskimo children is among the most lenient and positively supportive that has been noted in the entire cross-cultural literature. The child is kept in skin-to-skin contact under the parka next to the mother until it has reached a size which makes this difficult or until a new baby has been born, usually after nearly three years. (This birth spacing among Canadian Eskimos has been noted by $\mathbf{J}$. Briggs (personal communication) but she is unable to offer an explanation as to how it is achieved.) The child's nurturant needs are rapidly and easily met. Such close intense relationships lead to the development of a generally secure and optimistic ego. The child becomes confident that the universe is essentially benign. This core of basic trust provides a security which, though modified by other experiences, remains with the Eskimo throughout his life.

This early security and support is reinforced in later childhood. Toilet training tends not to be harsh, but more at the child's than the adult's insistence. (Though as we shall see there are aspects of this that are misleading). The child is generally permitted to eat, sleep, play and to do whatever whenever and however it likes. It is rarely frustrated, and there is a strongly stated overt value of noninterference in the life of others, even of a child, which mitigates against disciplining. This would tend to lead to a confident secure somewhat self-centered adult, generally free from psychic stress.

However there are other more covert aspects to Eskimo socialization which complicate this emergent early security system and the adult behaviour flowing from it. Eskimo infants very rarely fuss in the parka hood. This is not only because they are so content, but also because Eskimo mothers seem highly intolerant of fussiness. They signal the infant, often wordlessly by body stiffening, etc., when they want it to calm down. The child quickly learns to respond to these subtle cues which, because of his immature emotional and cognitive development, carry to the infant the implicit threat of the removal of support and nurturance. Also the child responds to the mother because of its identification with her. This first socialization message which the child receives is continually 
reinforced through life; the child learns that he must always be concerned with subtle cues from others for approbation or disapprobation of his behaviour.

At the same time that this is occurring, or very shortly beforehand, the infant, when around 7 to 10 months old, is learning to distinguish self from mother. The very closeness of self and mother however I believe retards this development for Eskimos and is the genesis of the optimistic, global, oceanic attitudes so characteristic of them, and also accounts for their being self-centred which is so strongly socialized against.

That is, if the infant really comes to think of himself as the centre of the universe and to experience very little frustration, he may have minimal tolerance for later frustration. His tendency toward rage when frustrated would also have to be stringently socialized. This I believe is the genesis of the socialization against aggression and selfishness in Eskimo children.

An additional factor enters into the child's life at about one year to fifteen months when he begins to be subjected to sporadic and unpredictable teasing. This teasing continues until the child is four or five, then diminishes in intensity as the child's responses become less overt. Specifically relatives or visitors will tease the child about its desire for the breast. The infant will turn in rage for support from its mother, but that is not forthcoming. The child is then teased for its rage. Learning its rage avails it little, it begins to develop the ability to withdraw emotionally from people in the face of adversity. Teasing is inconsistent; sometimes a child will be teased for urinating or defecating in inappropriate circumstances, though there has been no previous pressure for conformity.

To sum up briefly the child is trained against aggressiveness and selfishness, both traits of which are expected results of certain aspects of socialization. The child also learns to control his anger at the intrusion of others upon his autonomy and most importantly learns that all crucial controls over one's behaviour are initiated outside the self. He learns to seek to know what others think of him, and yet to be angry if these attitudes are not positive. Faced with others who have identical expectations he tends to smile a lot and avoid conflict.

He learns a general confidence about the physical universe and his prowess in it, primarily based on his early socialization, yet he learns to distrust the interpersonal world because of its inconsistent intrusions. In adult life a lack of success in hunting is seen as usually the result of some minor taboo breakage (the universe withdraws nurturance just as mother did), restitution by counter phobic taboos brought back the game (just as doing the inexplicable things mother wanted brought her approval). One could only fatalistically await a change. That is, the infant is teased or denied affection for things over which it has no control, such as being itself, a baby. The teasing or withdrawal of affection stops when one responds not to one's own needs but to others' attitudes. Thus, even though the universe can be manipulated, the Eskimo sees it as somewhat arbitrary.

If at times the mother, who is generally loving, becomes unloving (incapable of feeding) or frustrating because of physical circumstances over which she has no control the child can only understand this as talion for some unclear offense. Since the general permissiveness is so great, the occasions of frustration must be totally puzzling to the child.

Depending upon the stage of psychosexual development of the child, causes 
of frustration are interpreted in a variety of magical ways and Eskimo folklore reflects the various kinds of phobic responses which are developed to deal with this rare and incomprehensible experience. These include multitudes of taboos, beliefs in the interdependence of all life (oceanic feeling) and therefore the difficulty of avoiding conflict, but the necessity to do so.

Specifically, the chief way of handling the puzzling and apparently arbitrary frustrations engendered by the mother and by life is either retreat, not possible in some situations, or recourse to a belief in taboo breakings as the cause of misfortune. Therefore, a good hunter in the past believed he suffered reverses because he had broken one of the innumerable taboos which were so extensive that some always must be broken at one time or another by everyone. (This again suggests a fatalistic Eskimo response, how can one help breaking taboos - how can one help being a baby?)

There was little in the way of aboriginal witchcraft according to Carpenter (1953), and this is supported by my Alaskan observations. The belief in talion punishment for one's own actions, I believe, may have permitted immanent justice to be attributed to the universe and obviated the need for paranoid projections attached to other persons.

As culture contact increased, Eskimos perforce gave less credence to the ancient taboos as missionaries and others denigrated such beliefs; but still misfortunes occurred. Missionaries, however, provided a new set of taboos, mostly sexual. Carpenter believed that that was the point at which the Aivilik turned to witchcraft as an explanation for reverses or problems. He suggested, as already noted, that this was related to reality concerns.

What he details in 5 cases shows a mixture of the belief in taboo-breaking, the older pattern of inexplicable unavoidable fate and the newer pattern of projection of guilt, as the core of the 5 witchcraft cases. There seems to be a continuum present which includes the older expected Eskimo concerns, and changes in those patterns still within the older framework. In fact, what Carpenter sees as witchcraft here has the form of unacceptable guilt projected outward so that punishment can be seen as coming from outside the individual, not inside, but it still appears to have aspects of immanent justice, ideas of taboo breaking, etc., appended. $\mathrm{Re}-$ member, the Eskimo from infancy to adulthood has had to learn that no matter how much he wishes to be the centre of the universe, he must fear others' aggression for the same reason he fears his own. Such egoism leads to aggressive feelings when the individual is impinged upon. Secondly he has come to learn he must depend on subtle outside cues to determine his proper behaviour. In their absence he becomes disoriented or completely egocentric.

For example, among Eskimos much anger and hatred are suppressed as a result of the abovementioned socialization pattern. Thus when death comes to someone, many people may feel guilty since they had often unconsciously wished for it. This guilt must then be handled not through the belief that the dead person had broken a taboo, but by the unconscious belief that some person had caused the death by his infantile aggression wishes. Remember also how angry the child must be to be dispossessed of the abundantly supportive mother by a new infant, and how he had to displace this anger.

In one case, Carpenter relates, a man believed he had bewitched his wife to 
death, probably reflecting a covert aggressive wish directed against her, and that he was haunted by her spirit afterwards. His guilt allowed him to feel talion punishment from the spirit for his forbidden wishes. Belief in a kind of witchcraft which was really his infantile omnipotence reasserting itself permitted him to believe he had killed her. Because of his unwillingness to accept guilt, he permits his punishment to come from elsewhere reflecting his belief in immanent justice and his oceanic feelings, as well as the belief that all sanction is external. Moreover, this belief had strong cultural support in the Eskimo belief in soul transmigration, and the power of free-floating spirits to cause harm. As we have noted above this was, in any event, the only acceptable way for Eskimos to explain misfortune. But the agent now seems to have changed from impersonal spirits to a more personal ghost. Even so, it is not clear that fear of ghosts was absent in the past.

In another case, a woman committed theft, a strongly tabooed act. The guardian spirit of her victim then haunted her to death. Here again, guilt was felt over tabooed acts, but as in the above case, the individual was forced to use a talion self-punishment from an outside force, supported by older cultural beliefs in spirit powers.

In yet another case, it was believed that a certain woman was possessed because of a guilt acquired through her parents, which seems to fit with traditional beliefs both in reincarnation and in the arbitrariness of the universe. This was a psychically more primitive form of psychological problem. In the first two cases the cause of the guilt was known to the offenders; in the third case the more traditional pattern of taboo-breaking was involved; that is, it was unknown even to the victim (except insofar as archaic oral incorporation and identification with the mother was concerned).

In a fourth case, spirit possession resulted from guilt over masturbation which is a new taboo recently introduced by missionaries. This guilt combined with an inherited parental guilt which was disabling the woman. The woman's mother was believed to have been responsible for the father's death. The father after death sent a spirit to attack the daughter.

Here, it would appear that the traditional anxieties about control of aggressive feelings, which were magically believed to have caused the father's death were integrated with an identification with the mother. This has strong cultural support since Eskimos believe in soul transmigration. Furthermore, if one really feels omnipotent, then all things in the universe are actually one's responsibility.

We can only surmise that the masturbation, which is a regression to pre-genital organization, probably reflected oedipal conflicts. If the woman had identified with her mother, and had both wished for her father sexually and was angry with him for not granting her sexual favours, she may well have been fearful that his death was complexly the result of her aggression and her sexual drives. Talion punishment would have to result.

Finally, in another case, the ghost of a woman, who had died from tuberculosis, blamed her husband for her death and was believed to have bewitched him. Here, again, the problem of aggression, probably unconscious, which was the primary evil which Eskimos socialized against, is clearly the genesis of the possession fear.

The pattern seems relatively clear. Instead of classic projections of unaccept- 
able impulses onto others who are punishing witch figures, these cases all seem to be of possession by the spirits of the already dead. It is believed that most of these are talion responses to known "evil acts." Some acts involve the older pattern of taboo breaking, in one case, by parents. This reflects the earlier pattern of the inexplicable universe which punishes arbitrarily and also reflects the close identification of parent and child. But even in those cases, where guilt is known, the guilt is concerned with the violation of prime socialization directives (against aggression or theft). We have noted that theft and aggression tend to be normally expected drives of the very lenient child-rearing already discussed.

Since to Eskimos unconsciously-perceived aggression is never consciously acceptable, guilt is hard to admit. Therefore, punishment for vaguely perceived ill-doing is felt to come from outside but significantly from parents or parental imagos. The significance is that parental introjects are in reality what finally comes to make up guilt - the superego. The tension seems to exist between that aspect of the self which egocentrically denies that anyone else is important and is furious with the intrusions of others outside the self whom it must take into account, and that aspect of the self which is developed into a more "normal" superego. Such witchcraft can usually only be overcome by admission of guilt which is difficult for the oral optimist as we have shown, and is even more difficult, since the particular guilt is for such unacceptable (to Eskimos) impulses. Carpenter (1953) himself was able to help one bewitched man by giving him aspirins (which offered another kind of magic to counter the witchcraft without his ever having to face up to his own guilt).

In explanation, I would suggest that the oral character has difficulty relating the arbitrariness of the universe's treatment of himself to his own optimism and omnipotent feelings. The aboriginal recourse was to a belief in taboo violation as the cause of misfortune, which provided an omnibus explanation based on infantile talion anxiety and was reflected consciously in a kind of overt fatalism. As guilt over sexual activity was introduced by missionaries, and as disbelief in taboos was fostered, the organization of defences shifted toward a more paranoid orientation which still had strong elements of taboo concerns, and intrapunitive guilt. That is, in the past, the individual was expected and encouraged to do what he wanted, and thus had little guilt over most acts. In fact, there was so little censure, overtly, that one could do whatever one could get away with. But there was always the shame - concern with what people would think. What guilt existed was very archaic and related to oral incorporation and "bad mother" fears. Taboo-breaking was always a problem but at least one was not "guilty," but simply inappropriate in his acts. That is, one had to suffer the shame of exposing one's inappropriate acts to the spirits as one's inappropriate social acts would be noted and subtly censured by friends.

When the taboo on sexual activity replaced other taboo concerns, it generated unacceptable levels of intrapunitive guilt. This guilt then had to be at least in part projected onto witches since guilt was so hard to accept, but retained the character in part of being related to inadvertent taboo-breaking, which both made one responsible for others' misfortunes and provided an explanation for talion punishment by witches for breaking these taboos.

In this case, the cultural changes in religious beliefs acted in part to change 
the direction and the object of psychic defences, while a core of basic concerns, related to the modal personality structure, remained.

There is a great deal more that might be said about, for instance, Eskimo passivity, fatalism, avoidance of conflict, suicide as a response to frustration and fusion needs, and acceptance of the universe as an unchangeable fact about which little can be done; these considerations weave a complex interlocking picture which is beyond the scope of this paper.

What I am suggesting, however, is that what Carpenter saw as a new phenomenon for dealing with anxiety, really has many aspects of older patterns, and that the changes are not so dramatic as he suggests. Furthermore, it is suggested that the form of pathological response is not a phenomenon sui generis but involves a resolving of existing predispositions based on personality structure and cultural forms, which may be put under special stress by acculturative change.

\section{BIBLIOGRAPHY}

BOYER, B. 1964. Folk psychiatry of the Apaches of the Mescalero Indian Reservation. In: Ari Kiev, ed. Magic Faith and Healing. New York: Free Press of Glencoe. pp. 384-419.

BRIGGS, J. 1970a. Kapluna daughter: living with Eskimos. Trans Action, 7: 13-24.

1970b. Never In Anger. Cambridge: Harvard University Press. 379 pp.

CARPENTER, E. S. 1953. Witch fear among the Aivilik Eskimos. The American Journal of Psychiatry, 110(3): 194-99.

DEVOS, G. A. and A. E. HIPPLER. 1969. Cultural psychology: comparative studies of human behavior. In: G. Lindzey and E. Aronson, eds. Handbook of Social Psychology, Vol. IV, 2nd ed., Reading, Massachusetts: Addison Wesley Publishing Company. pp. 323-417.

FESTINGER, L. 1962. Cognitive dissonance. Scientific American, 207: 93-102.

FREUCHEN, P. 1931. Eskimo. New York: Liveright, Inc. 320 pp.

FORTUNE, R. 1932. Sorcerers of Dobu. New York: E. P. Dutton and Co. 326 pp.

HIPPLER, A. E. 1970. Eskimo Acculturation: A Selected, Annotated Bibliography of Alaskan and Other Eskimo Culture Change. Fairbanks: Institute of Social, Economic and Government Research, University of Alaska. 209 pp.

KIEV, A. 1962. The Psychotherapeutic aspects of primitive medicine. Human Organization, 21(1): 25-29.

KLEIN, M. 1932. The Psychoanalysis of Children. London: Hogarth Press (1950). 393 pp. кLuскнон, с. 1944. Navajo Witchcraft. Boston: Beacon Press. 254 pp.

LEwIN, B. 1950. The Psychoanalysis of Elation. New York: Norton. 200 pp.

LUBart, J. 1971. Psychodynamic Problems of Adaptation-Mackenzie Delta Eskimos. Ottawa: Northern Science Research Group. MDRP \#7. 49 pp.

MARwick, M. G. 1952. The Social Context of Cewa Witch Belief. Africa, 22: 120-35; 215-33.

NADEL, S. F. 1952. Witchcraft in four African societies: an essay in comparison. American Anthropologist, 54: 18-29.

1954. Nupe Religion. New York: Free Press of Glencoe. 288 pp.

ROHEIM, G. 1940. On Freud and cultural anthropology. The Psychoanalytic Quarterly, 9: $246-55$. 
1950. Psychoanalysis and Anthropology. New York: International Universities Press. 496 pp.

1952. The Gates of the Dream. New York: International Universities Press. $554 \mathrm{pp}$.

ROSENTHAL, T. and B. v. SIEgEL. 1959. Magic and witchcraft: an interpretation from dissonance theory. Southwestern Journal of Anthropology, 15: 143-67.

WHitTEN, N. E. 1962 . Contemporary patterns of malign occultism among Negroes in North Carolina. American Folklore, 75: 311-25.

WITTKOWER, E. D. and H. H. WeIDMAN. 1968. Magical thought and integration of psychoanalytic and anthropological theory. Transcultural Psychiatric Research 5: 125-30. 